\title{
Editorial Foreword 71.4 (November 2012)
}

\section{Our Cover}

Cover image: Ishikawa Toyonobu, Iro tsubana [Love's tufted grasses], ca. 1750s, frontispiece, woodblock print on paper, collection of GREGORY M. PFLUGFELDER. In this illustration from an eighteenth-century Japanese book, a youth arranges irises, a traditional symbol of young male beauty. His distinctive hairstyle and clothing mark him visually as a wakashu: a male who has graduated from boyhood but not yet achieved adult status. According to early-modern Japanese social semiotics, the topknot was supposed to be bound throughout the remainder of the secular male's life course, whereas the shaved patch of crown would, upon assumption of adulthood, expand forward over the pate, erasing the forelocks. The swinging sleeves of the youth's kimono, with their cherryblossom design, likewise encode a pre-adult-male status.

\section{Thematic Issue: Gender Across Asia}

Over the course of my career, many individual Journal of Asian Studies articles and bundled sets of pieces published as symposia or forums in these pages have influenced my thinking on topics that already interested me. Many others have made me aware of theories, texts, and sometimes even whole subject areas that I had never considered. But looking back over my three decades as a regular reader of the JAS, which began when I started graduate school in 1982, there are also two issues, qua issues, that stand out in my mind as having made a particular impact on me. One was the May 1994 issue, the article section of which was given over completely to studies of nationalism. The other was the August 2000 issue; all of the articles dealt with spatial and geographical concerns. When the former appeared, I was intensely interested, as I still am, in Chinese protest movements, which have often had nationalist inflections. And when the latter was published, I was working on a book on Shanghai and wrestling with how to define the city in spatial and geographic terms. In both cases, it was eye-opening to be able to read through an issue in which scholars in a range of disciplines, experimenting with diverging approaches, and with primary interests in varied parts of Asia, approached a given broadly defined topic. The experience changed the way that I thought about a variety of texts and questions, and they also simply made for interesting reading, given the way that the concerns of specific authors both intersected and diverged.

In spite of how much I valued that pair of earlier special issues, I was hesitant during my first years as Editor of the JAS to try anything comparably focused. 
This was due in large part to the many high-quality submissions that were continually coming in on diffuse topics-something that even led me to back away, to some extent, from the useful grouping together of pairs, trios, and quartets of articles that some of my predecessors had done, often to very good effect. To put together a special issue, I feared, would mean delaying publication of very worthy work that did not fit under a given rubric. Now, however, for a variety of reasons, I feel that the time has come to end the self-imposed moratorium on special issues - and the result is this one devoted exclusively to the subject of gender. One reason for this is simply the importance of the topic. Another is that, as a rubric, it seems both suitably capacious and yet not so abstract as to be all-encompassing. Many individual pieces have appeared in the JAS over the years, of course, that deal with one or another facet of gender, and some of the most compelling pieces I have run during my own time as Editor have addressed the subject. The JAS has never, though, devoted an entire issue to gender. It felt like the time had come to rectify this-and that many subscribers to the journal could benefit from an issue that would not promote a specific approach to gender, but rather would offer a set of deeply informed soundings on the gendered dimensions of many different phenomena. Rather than limiting ourselves to a particular genre of essay, a particular sort of gender analysis, or specific settings, the goal is in part to show many different kinds of contributions to Asian studies.

In the end, pulling together the materials for the issue we envisioned turned out to be a surprisingly easy undertaking. One thing that simplified the process was that a group of fascinating separate submissions relating to gender had already been submitted over the transom and were moving independently toward publication. From the beginning, I was targeting the date for the issue that would include Gail Hershatter’s Presidential Address, since she had let me know that it would focus on gender. After that, all it took was brainstorming with the editorial board and Managing Editor Jennifer Munger, all of whom had excellent ideas of new pieces to solicit to complete the issue and expand its geographical and disciplinary coverage, which was never intended to be all-encompassing but I did want to be wide-ranging. The result is a volume that includes contributions that fit into all of the journal's main genre categories: there is a "Beyond the Headlines" essay, a "Trends" piece, the Presidential Address, a series of research articles, and a forum, complete with a commentary in the form of an introduction. They range as widely in terms of place and approach as any past issue that comes to mind. And this simply offers clear proof, if any were needed, that in Asian studies as well as in the field of history there is validity to the claim that Joan W. Scott made in her now-classic American Historical Review essay on gender's importance and flexibility as a category of analysis: nearly every category, from politics to storytelling and from fashion and the body to debates on nuclear energy, can be enriched, recast, rethought, and seen anew if viewed through the lens of gender. ${ }^{1}$

${ }^{1}$ Joan W. Scott, "Gender: A Useful Category of Historical Analysis," The American Historical Review 91, no. 5 (Dec. 1986): 1053-75. 
The two special issues of the JAS mentioned above both came with extended introductory essays, in the earlier case written by the then-current editor of the journal, David Buck, in the later one by a trio of geographically minded scholars who had pulled the volume together: Marcia Yonemoto, Thongchai Winichakul, and Kären Wigen. In this case, rather than try to follow in their footsteps, I will content myself with a more conventional overview of the issue. This is largely because elegant overviews of how issues relating to gender in Japanese studies, Chinese studies, and Southeast Asian studies have been or might be handled are provided by the authors of this volume's three opening essays: political scientist Robin M. LEBLANC, historian Hershatter, and anthropologist Michael G. Peletz.

In addition, when it comes to goals for the issue and what I think it accomplishes, I feel that enough will be said if I quote from the thoughtful introduction that Harriet Evans and Julia C. Strauss offer to open "Gender in Flux," a recent special issue of The China Quarterly. ${ }^{2}$ They assert that what emerges from their collection is "the indispensability of gender as a critical category of analysis because of the insights about China that it offer[s]. .. . [T] he articles here do not conceptualize gender either as a fixed or stable category, or a well defined domain of study. Though they all focus on women's lives and experiences, gender emerges through them as an axis of social and subject formation in different spaces, forms and practices ... and suggest ways in which gender makes a difference-shedding new insight into Chinese society - through its connection with other dimensions of social and cultural practice." Change "China" to "Asia," "Chinese" to "Asian," and "women's lives and experiences" to "the lives and experiences of men and women," and this could serve as a good general summary of this issue.

\section{An Overview of the Articles}

This issue can be divided neatly into three parts: first comes a trio of essays, one apiece in the "Asia Beyond the Headlines," "Presidential Address," and "Trends" genres; next is this year's "JAS at AAS" roundtable discussion, the theme of which is "Sexuality and the State"; followed up by four research articles, all of which engage with the topic of gender. The issue's title is "Gender Across Asia," but surveying these three sections, I have realized that other "crossings" beyond geographical ones are involved. The issue also moves across disciplinary lines by including contributions by scholars of literature, language, and law, as well as historians, anthropologists, and political scientists. It also moves across periods, albeit never going back beyond the 1500s, and moves across the divide between masculinity and femininity, with some pieces focusing on the former, some on the latter, and some on the interplay between the two.

\footnotetext{
${ }^{2}$ Harriet Evans and Julia C. Strauss, "Editors' Introduction: Gender, Agency and Social Change," in Gender in Flux: Agency and Its Limits in Contemporary China, (Cambridge University Press, 2011), 9-10. Originally published in The China Quarterly, no. 204 (2010): 817-26.

${ }^{3}$ Ibid., 9-10.
} 
The issue begins with LeBlanc's evocatively titled "Lessons from the Ghosts of Salaryman Past: The Global Costs of the Breadwinner Imaginary," an exploration of the way that ideas about masculinity inflect Japanese discussions of everything from economic decline to nuclear power. The author, an ethnographically minded political scientist intrigued by discourse, provides a thoughtful look at how, in Japan, gender inflects such things as the legacy of World War II sacrifices and the notion that men have a special role to play in protecting the nation. Her "Beyond the Headlines" essay is both an ideal complement to the series of "one year after" pieces that appeared in the May issue, and a fitting first contribution to a special issue intended to showcase the widely varied topics that can be viewed productively through the lens of gender.

Next comes Hershatter's "Disquiet in the House of Gender" a Presidential Address that insightfully reflects upon a set of interrelated issues. The ways women contributed to and were represented in visual materials associated with the first decades of the People's Republic of China provide the starting point for a discussion that moves on to address the power of gender categories to alter people's sense of time and recast collective memory. Like many of the best AAS Presidential Addresses, what Hershatter has to say is rooted in a deep engagement with one part of Asia-China-but has much to offer to specialists working on all regions and countries. And again, like many of the best forays into this tricky genre, it both nods to the past and prods readers to do new kinds of work in the future, through commenting on how scholars of modern China both inside and outside of Asia have looked at gender in modern Chinese history.

This is followed by Peletz's "Gender, Sexuality, and the State in Southeast Asia," which is classified as a "Trends" piece since it combines a grand tour d'horizon of past scholarship on the topic with the presentation of illuminating analytical points. It was originally written for the JAS at AAS forum held at the annual meeting, but it seemed to work so well as a self-contained overview of topics of broad significance that we felt it was best placed on its own up at the front of the issue.

The second section of the issue begins with political scientist ELIZABETH J. Remick's "Introduction" to the "Sexuality and the State in Asia" forum. The first thing to say about it is that Remick provides a wonderfully succinct and yet comprehensive survey of the contents of the forum. The second thing to note is that she was not on the panel at the AAS meeting from which the forum emerged. Rather, she attended it and had such interesting things to say about what she had seen and heard that Managing Editor Jennifer Munger, who once again took the leading role in conceptualizing and organizing the event at the annual meeting, invited her to contribute a comment to this issue - carrying forward a tradition of adding new people to the "cooked" as opposed to "raw" version of the JAS at AAS forum that we began in 2010 with our first publication of the kind.

Rather than duplicate her skillful introduction of the pieces in the forum, all that I will do here is list them-and note that they all make for very stimulating reading. They are, in order, historian Gregory M. Pflugfelder's “The NationState, the Age/Gender System, and the Reconstitution of Erotic Desire in 
Nineteenth-Century Japan" (the essay to which this issue's cover image is linked); literary scholar KAM LOUIE's "Popular Culture and Masculinity Ideals in East Asia, with Special Reference to China"; historian Indrani ChatTerjee's "When 'Sexuality' Floated Free of Histories in South Asia"; and historian RACHEL LEOW's "Age as a Category of Gender Analysis: Servant Girls, Modern Girls, and Gender in Southeast Asia."

The quartet of research articles that close the issue-or rather close the section that is not given over to our usual range of book reviews-are a wonderfully varied lot. The first is historian SiYen FEI's "Writing for Justice: An Activist Beginning of the Cult of Female Chastity in Late Imperial China," which offers a new interpretation of the Ming Dynasty (1368-1644) origins of a much-discussed aspect of Chinese gender history. Following that is a piece by language and literature specialist Shobna NijHawan that moves between South and Southeast Asia and is titled "At the Margins of Empire: Feminist-Nationalist Configurations of Burmese Society in the Hindi Public (1917-1920)." After that comes "Marriage Mobility and Footbinding in Pre-1949 Rural China: A Reconsideration of Gender, Economics, and Meaning in Social Causation," a collaborative work by anthropologists Melissa J. Brown, Laurel Bossen, Hill Gates, and Damian Satterthwaite-Phillips. Closing the issue is legal scholar and Central Asianist Kara Abramson’s “Gender, Uyghur Identity, and the Story of Nuzugum." Whereas many contributions to the special issue revisit and recast issues that have been dealt with before in these pages-for example, we have run articles on footbinding before-this final one is, I believe, the first JAS article ever to foreground the gendered aspect of life and memory in Xinjiang.

\section{Forthcoming Articles in JAS 72:1 (February 2013)}

From Stars to the State: Globalization, Identity, and Asian Popular Music Jennifer Milioto Matsue

Adapt or Voice: Class, Guanxi, and Protest Propensity in China Yang Su and Shizheng Feng

Methamphetamine Solution: Drugs and the Reconstruction of Nation in Postwar Japan

Miriam Kingsberg

The Limits of the State: Coercion and Consent in Chinese Tibet Fernanda Pirie

“The Yalu River Era of Developing Asia”: Japanese Expertise, Colonial Power, and the Construction of Sup'ung Dam

Aaron S. MoOre 
Translingual World Order: Language Without Culture in Post-Russo-Japanese War Japan

SHO KONISHI

The Bali Bombings Monument: Ceremonial Cosmopolis Jeff Lewis, Belinda Lewis, and I Nyoman Darma Putra 